\title{
Psychological Construct and English Vocabulary Learning: A Structural Equation Modeling Approach
}

\author{
Hamid Mohammadi (Corresponding author) \\ English Department, Islamic Azad University (IAU), Ahar Branch, Iran \\ E-mail: hamid.mohammadi27@yahoo.com
}

Received: July 18, 2014 Accepted: July 28, 2014 Published: July 28, 2014

doi:10.5296/ijele.v2i2.6039 URL: http://dx.doi.org/10.5296/ijele.v2i2.6039

\begin{abstract}
Drawing upon the data from 465 EFL learners in Iran, this paper is an attempt to presents a structural equation model that integrates vocabulary knowledge and Psychological construct to outlines the result of experienced motivation and anxiety language learners with respect to various differences in genders and language proficiency. Using the survey method, in this study the measures for the intrinsic and extrinsic motivation were tailored from Schmidt, Boraie and Kassabgy (1996). The measures for instrumental, integrative and cultural interests were tailored from Dörnyei (1990) and were piloted to examine its validity and reliability. On the basis analyses of structural equation modeling, the results indicated that motivation significantly predicts the English vocabulary achievement of the learner within an Iranian context. On the other hand, English learning anxiety had negative relationship on English vocabulary learning for the different levels of language proficiency groups, especially for learners in the intermediate group. In comparing male students with female students, low-intermediate with upper-intermediate certain group differences were found. Broadly speaking, learner's instrumental motivation is usually a preferred way of learning English vocabulary, and their levels of English language class anxiety were higher than their levels of English use and test anxiety.
\end{abstract}

Keywords: Anxiety, Motivation, Iranian English learner, Structural equation modeling 


\section{Introduction}

Language is one of the crucial element of the society and culture of the people who speak it. By choice or force, in the 21st century, English is widely recognized as the international language both in and out of the field of TESOL (McKay, 2002). It has been used to serve various purposes. It is difficult to arrive the exact number of English users due to the ambiguity in the definition of English user and lack of statistical information, but crystal (2003) estimated it to be somewhere between 1.1 billion and 1.8 billion, 320 million to 380 million of which are native speakers of the language (Mastuda, 2012). Consequently, in order to achieve English abilities, a plethora of language tests has been developed and used internationally for these users.

Advances in language testing do not take place in a vacuum; they are stimulated by advances in our understanding of the processes of language acquisition and language teaching. And development in language testing can provide both practical tools and theoretical insights for further research and development in language acquisition and language teaching (Bachman, 1990). Test-takers' motivation and anxiety are two major psychological factors associated with test-takers' performances (Gardner, 1985; Horwitz, 2001; MacIntyre, 2002). Motivation of the students is one of the most important factors influencing their success or failure in learning the language (McDonough, 1983). Researchers also indicated that the differences in language achievement are partly related to gender differences in motivation, L2 learning anxiety, and test anxiety (Baker \& MacIntyre, 2000; Kitano, 2001; MacIntyre, Baker, Clément, \& Donovan, 2003).

\subsection{Motivation}

When we think of individual differences among language learners, motivation springs quickly to mind as one of the most important of these variables (Robinson, 199). Motivation plays a seminal role in any learning task. It affects our choice of what to learn, our persistence at doing a task, and our effort exerted toward achieving a goal (Clark, 2000; Pintrich \& Schunk, 2002). Therefore, it is no surprise that researchers in the field of SLA have looked at the role of motivation in learning an L2 and have found that motivation strongly influenced proficiency and success in a L2. In the classroom context, motivation can be seen as continues interaction process between the learner and the environment (Nutting, 1985). Although, neither the theoretical nor the empirical literature of motivation has so far shed enough light on the field of L2 vocabulary learning therefore, it is logical to assume it is the pushing wheel of the learning vehicle that students ride to reach their educational objectives. Thus far, only a small number of studies have been undertaken to examine the role of motivation in vocabulary learning (Laufer \& Hulstijn, 2001, cited in Ta Tseng \& Schmitt).

Motivation is multifaceted, complicated subject encompassing many theories. It was developed in the nineteenth century by the psychologist Sigmund Frued (1964, cited in Chamber, 1999). It has been defined in many different ways by different researchers in Psychology and other scientific disciplines. Klenging and Kleinginna (1981) present 102 statements referring to the concept. A simple definition is therefore, not possible. Keller 
(1983) states, "Motivation refers to the choice people make as to what experiences or goals they will approach or avoid and the degree of effort they will exert in this respect" (P. 389).

Behaviorists explain motivation with concepts such as "reward" and "incentive". A reward is an object or event supplied as a consequence of particular behavior that we think is attractive. An incentive is an object or event that actually motivates a person's behavior. Humanistic theories of motivation share a belief that people are continually motivated by inherent needs to fulfill their potential for "self-actualization" (Malow, 1968, 1970), the inborn "actualizing theory" (Rogers \& Freiberg, 1994), or "self-determination" (Deci, Vallerand, Pelletier, \& Ryan, 1991). From the humanistic perspective, motivating students means encouraging their inner resources (Reeve, 1996).

Cognitive theories of motivation also developed in reaction to behavioral views. Cognitive theorists hold that behavior is determined by our thinking, not simply by whether we have been reinforced or punished (Schunk, 1996b; Stipek, 1993). One central assumption in cognitive approaches to motivation is that people do not respond directly to external event or physical conditions such as hunger but, rather, to their interpretations of these events. Lastly, according to sociocultural view of motivation, people engage in activities to maintain their identities and their interpersonal relations within a community, which is often referred to as a community of practice. To learn is to participate in the practices, the life of the community. Thus, students learn how to be students by watching and learning from classmates and peers in the school community.

From original study, Gardner and his colleagues developed the Socio-educational model of L2 motivation (Gardner, 2001; MacIntyre, MacMaster, \& Baker, 2001). In the socioeducational model of second language acquisition motivation was assessed in terms of three components, the desire to learn the language, attitude toward learning the language, and motivational intensity (i.e. the effort extended to learn the language). Any one of these elements on its own does not adequately assesses the construct of motivation; the tripartite assessment does, however provide a fairly good estimate of motivation in all of its complexity. In fact, Tremblay and Gardner (1995) added additional measures of motivation to a structural equation model of second language acquisition and found the model to be consists with those previously reported using only the three component of motivation described above. Gardner (1985), in defining motivation, argues that four elements must be presented for a student to be considered motivated: a goal, desire to achieve the goal, positive attitudes, and effort. Gardner has referred to these as "affective variables", clearly differencing them from the more purely cognitive factors associated with language learning such as intelligence, aptitude and related variable.

The socio-educational model simply purposes that the cultural component of language learning motivation plays a role in language classroom motivation in that students' reaction to the classroom is influenced in part by cultural component. It is further proposed that research on the educational component should take into account the very special cultural component involved in learning a second language, which in most cases does not relate to the learning of other school subject matter. Whereas the socio-educational model of second language 
acquisition posits that that the cultural component can play a role in language classroom motivation, it also posits that the educational component would not be expected to play a role in the cultural component of a language learning motivation.

Gardner's (1985a) social psychological approach assumes that students' goals, when they engage in L2 learning, fall into two categories, an integrative orientation, and an instrumental one. An integrative orientation reflects a positive disposition toward a community of L2 speakers, accompanied by a desire to learn the L2 for the purpose of interacting with, and even becoming similar to valued members of the community of L2 speakers. An instrumental orientation refers to a desire to learn the L2 primarily for potential concrete gains associated with L2 proficiency, such as improved education, career, or financial prospects.

L2 motivation research has witnessed a shift of focus after the publication of Dörnyei (1998) process model of L2 motivation. As a result, in the late 1990s, a new, process-oriented period began for L2 motivation research. The process-oriented period is characterized by an increasing emphasis on viewing motivation, not simply as a static product, but also as a dynamic process fluctuating over time. This movement is spearheaded by the research that has been carried out by Dörnyei, Ushioda ( 2001), and colleagues in Europe. Dornyei (1994) argues that in order to grasp the array of variables and processes involved at this level of L2 motivation, it appears useful to separate three sets of motivational components as following:

1) Course-specific motivational components concerning the syllabus, the teaching materials, the teaching method, and the learning tasks.

2) Teacher-specific motivational components concerning the teacher's personality, teaching style, feedback, and relationship with the students.

3) Group-specific motivational components concerning the dynamics of the learning group.

The types of goals we set influence our motivation. Goals that are specific, moderately difficult, and likely to be reached in the relatively near future tend to enhance motivation and persistence (Pintrich \& Schunk, 1996; Stipek, 1996).

\subsection{Anxiety}

Although everybody has experienced feeling of anxiousness, like motivation, it is not easy to define in a simple sentence. It is associated with feeling of uneasiness, frustration, and self doubt, apprehension, or worry (Scovel, 1978). The socio-educational model proposed by Gardner, also integrated the role of anxiety into the model. The model assumed that individual differences in achievement would be influenced by intelligence, aptitude, motivation, and anxiety. Situational anxiety affected not only formal language training but informal language experiences. Thus, the instrument to measure attitudes and motivation-the attitude /motivation Test battery developed by Gardner(1985) also included a anxiety measure (Young, 1999).

During the course of developing the socio-educational model, Gardner has worked with other researchers, especially MacIntyre, to explore the issues of language anxiety and developed more measure scales such as classroom Anxiety scale and French use anxiety scale from the 
French class anxiety scale (MacIntyre /Gardner, 1989). MacIntyre and Gardner argued, language anxiety, was the apprehension experienced when a situation requires the use of a second language with which the individual is not a stable personality trait referring to the propensity for an individual to react in a nervous manner when speaking, listening, reading, or writing in the second language (1994).

They (1994) remarked that language anxiety was characterized by derogatory self-related cognitions, feeling of apprehension, and physiological response such as increased heart rate. In the case of second/foreign language learning, fear of negative evaluation was likely to be manifested in a student's overcome with academic and personal evaluations of his/her performance and competence in the target language (MacIntyre/Gardner, 1989).

The research on anxiety suggests that, anxiety can be experienced at various levels (Oxford, 1999). One of the earliest and most prominent figures to investigate foreign language Anxiety, a particular type of situation specific anxiety, is Horwitz, the principal investigator for several studies in this area, who advanced a general theory about foreign language classroom anxiety (Horwitz, 1995; 2007 et al, 1986, Horwitz/young, 1991). Just as Scovel claimed that foreign language anxiety was not a simple unitary construct, but a cluster of affective states influenced by factors which are intrinsic and extrinsic to the foreign language learner (1978); Horwitz et al. described foreign language classroom anxiety as a distinct complex of self perceptions, benefits, feelings, and behaviors related to classroom language learning arising from the uniqueness of the language learning process" (1986, P. 128).

Horwitz et al a (1986) claimed that there were three component of foreign language anxiety communication apprehension, which played a larger role in foreign language anxiety, was a type of shyness characterized by fear of or anxiety about communicating with people (1986).

Test anxiety referred to a type of performance anxiety stemming from a fear of failure (1986). Test anxious students often demanded more than that could do and worried about their performance. Fear of negative evaluation, which might occurs in any social and evaluation situations and the expectation that others would evaluate oneself negatively" (Watson/friend, 1969, cited in Horwitz et al, 1986). Like communication-anxious individuals, people who feared negative evaluation rarely initiated conversation and interacted minimally (Georgesen/ Horwitz, 2002), language students who experienced this anxiety tend to sit passively in the classroom, withdraw from activities counterparts, however, their level of achievement often did not reflect that effort.

Scovel (1978, cited in Ellis, 1977) draws attention to Albert and Harber's (1960) distinction between facilitating and debilitating anxiety. The former motivates learners to 'fight' the new learning task, prompting them to make extra efforts to overcome their feeling of anxiety, and the latter causes the learners to' flee' the learning task in order to avoid the source of anxiety.

\subsection{Literature Review}

Regardless of whether researchers espoused the soci-educational model or incorporated other theories or models of learning to language learning motivation, numerous studies have shown 
the impact that motivation has on L2 success. For instance, Dornyei and Clement (1990) in their study reports on the results of a large-scale motivation survey in Hungary. The affective dispositions of school children toward five different target languages (English, German, French, Italian, and Russian) were assessed. The study result revealed that Hungarian language learners' general motivational disposition toward different target languages is consisted of five broad dimensions: Integrativeness, Instrumentality, Direct Contact with L2 speakers, Media Usage (or "indirect contact"), and Vitality of L2 Community. The main language specific effect that has emerged was the fact that with certain languages some of these components have merged together into a broader disposition or have split up into subdimensions, depending on the perceived ethnolinguistic vitality of the L2 in question.

It also found that marked gender differences in terms of the boys' and girls' dispositions toward the different languages. Girls in general tended to score higher on most motivational measures, the only main exception being three factors related to the German language. A comparison of girls' and boys' language choice preferences confirmed that German -along with Russian - is indeed a more "masculine" language, whereas French and Italian are more "feminine" •

With regard to Iranian context, some studies have been undertaken to investigate learners' motivation towards the English language. For instance, Najafi and Behjat (2013) in their study among the 80 Iranian female students from high school students tried to find out the relationship between the rise and fall of Iranian female students motivation and their different levels of language proficiency from high school to university and to discover whether the motivation of Iranian female students at different proficiency levels change over an academic semester. Their study was conducted in Mazandaran, Iran. They tried to answer the following research questions: 1-Does the motivation of Iranian female students at different proficiency levels change over an academic semester? 2-Is there any relationship between female students' language proficiency score and the rise and fall in their motivation? 3-What are the possible reasons behind the rise and fall of motivation for students at different proficiency levels?

The analysis of the data revealed that there is a statistically significant difference in the motivation level across different language proficiency groups over an academic semester. In addition, the result indicated that there are significant positive relationship between the participants' motivation scores and their language proficiency scores. Finally, the result revealed that there are five demotivating factors responsible for the rise and fall of motivation for students at different proficiency levels including learning contents, materials, and facilities; attitude towards English speaking community; the teacher; experience of failure, and attitude towards second language learning. Among these, learning contents, materials, and facilities are the most prominent demotives in L2 learning, and attitude towards second language learning is the least important source of demotivation.

With respect to anxiety, in most notorious study MacIntyre and Gardner (1989) studied 94 first year college students in Canada using nine anxiety scales: classroom anxiety, French use anxiety, trait Anxieties, computer anxieties, test anxieties, audience sensitivity, state anxieties, 
paired associates and vocabulary test. The results supported Horwitz et al.'s (1986) generalizations concerning communicative apprehension and social-evaluative anxiety, which were shown to have negative effect on production. The students with high communicative anxiety tended to have lower scores on free recall on the paired-associates learning task and oral and written vocabulary tests. Thus, the researchers concluded that the result presented tend to indicate that anxiety leads to deficits in learning and performance (1989). In addition, test anxiety was founded to be a general problem and not specific to the language classroom. It influenced language course grades both positively and negatively. State anxiety was shown to be a product rather than a predictor of performance. The study revealed that communication apprehension and social evaluation were part of the elements of foreignlanguage classroom anxiety.

In another important study, Aida and Kitano (2001) tried to find the relationship between language anxiety and Japanese language learning. It was found that foreign language anxiety was inversely correlated with language performance. In addition Aida (1994) found that experience had a significant effect on anxiety. Students with experience in Japan showed a significantly lower level of anxiety in the classroom. Moreover, female students were found to score higher than males. They concluded that student's anxiety level were significantly positively correlated with their fear of negative evaluation and decreased perception of their own ability in the target language.

In short, these studies have shown that high motivated students often perform better in the target language and they demonstrate superior native language skills than low motivated students. It can be concluded that foreign language anxiety is independent of the specific target language that FLCAS enjoy a higher reliability in measuring language anxiety.

\subsection{Purpose of the Study}

This study aims at investigating Iranian university students' psychological factors and these factors' relation to language test performance taking the Nation's vocabulary level test (VLT). The question of interest was whether and how vocabulary test-takers' motivation, anxiety, contribute to VLT performance. Identifying prominent VLT test-takers' characteristics and knowing how these characteristics are related to the students' VLT performance can contribute to the issues of test fairness and construct validity of the test. Larsen-Freeman (2001) states that success in learning a second language varies considerably and individual test-taker characteristics can contribute to the explanation of differential learning success.

Summarizing the rationale provided above, three research questions guided this study:

\subsubsection{Research questions:}

1. To what extent English vocabulary learning motivation and anxiety affect Iranian university students by gender?

2. To what extent English vocabulary learning motivation and anxiety affect Iranian university students by proficiency level? 


\section{Methods}

\subsection{Participants}

The sample pool in this study were 465 (453 male and 404 female) non-English major freshmen students with the average year of 20 . The valid questionnaires were 425 for this study. In order to achieve the aim of study, the learner took the Nation's vocabulary level test to place the participants in three groups of pre-intermediate and upper- intermediate. Descriptive statistics was used on the participant's proficiency test scores. Table 1 presents the basic statistical description for the participants' language proficiency scores.

Table 1. Descriptive statistics on the vocabulary test scores

\begin{tabular}{|c|c|c|c|c|c|c|}
\hline & $\mathrm{N}$ & Range & Minimum & Maximum & Mean & $\begin{array}{c}\text { Std. } \\
\text { Deviation }\end{array}$ \\
\hline $\begin{array}{c}\text { Vocabulary } \\
\text { Test }\end{array}$ & 425 & 83 & 15 & 98 & 65.28 & 23.627 \\
\hline
\end{tabular}

As Table 1 shows, the Vocabulary level test scores ranged from a minimum of 15 to a maximum of 98, with the mean of 65.28 .12 and a standard deviation of 23.627. Taking each participant's score, the researcher classified the students into two groups of lower intermediate and upper intermediate by considering one standard deviation above and below the mean. Those who scored 89 or higher were considered as upper-intermediate, those whose scores were 42 or lower were in the lower-intermediate group.

\subsection{Materials}

\subsubsection{Questionnaire}

The survey questionnaire had two major sections. Section one elicited students' demographic information, including their name, gender, major in university, the grade they started to learn English as a school subject and their hometown.

Section two consists of the experienced motivation and anxiety of the learners. In this study the measures for the intrinsic and extrinsic motivation were taken from Schmidt, Boraie and Kassabgy (1996). The measures for instrumental, integrative and cultural interest were taken from Dörnyei (1990). These consist of 34-item and designed to measure five dimensions of motivation: four items belonged to integrative orientation (questions 5, 15, 32, 33), four items belonged to instrumental orientation (questions 10,11, 24, 36), seven items belonged to cultural orientation (questions $6,7,16,19,23,34,35$ ), fourteen items belonged to extrinsic orientation (questions 2, 3, 4, 13, 14, 18, 22, 25, 26, 28, 30, 31, 37, 38); five items belonged to intrinsic orientation (questions: 1, 12, 21, 27, 29). Students' language anxiety levels were directly adopted from Horwitz et al. (1986), and consist of 24 items, on a 5-point Likert scale, 
with responses ranging from "strongly disagree" to "strongly agree" and was used to measure two dimensions of foreign language classroom anxiety: English use and test anxiety (questions 35 to 44), and English language class anxiety (questions 45 to 60).

\subsubsection{Vocabulary Level Test (VLT)}

V-test paper is adapted from Nation's vocabulary learning test (1990). According to Nation (1990), learners need to know at least these 2,000 lexical items because they cover approximately $87 \%$ of the words in an average text. It consists of 30 words from the second thousand most frequent words of English.

\subsection{Procedure}

In general terms, the procedure was carried out in two phases (pilot and main study) and university students in the center of Tabriz were participated in this study.

\subsubsection{Pilot Study}

A pilot study, with a sample size of 65, was conducted on April 14th, 2014 at the University of Tabriz. The main purpose of the pilot was to examine the reliability, validity of the questionnaire.

\subsubsection{Factor validity}

Since the Kaiser-Mayer-Olkin Measures obtained were .843, this calculation provides support for the use of factor analysis. The significant Bartlett's Tests of Sphericity for data questions $(\mathrm{X} 2=1158.74, \mathrm{df}=424, \mathrm{p}<.001)$ indicated that the correlation matrix is suitable for factor analysis by testing the hypothesis that the matrix is an identity matrix.

Table 3. Kaiser-Mayer-Olkin and Bartlett's tests

\begin{tabular}{|c|c|}
\hline $\begin{array}{c}\text { Kaiser-Mayer-Olkin } \\
\text { Measures of Sampling } \\
\text { Adequacy }\end{array}$ & 0.843 \\
\hline \multicolumn{2}{|c|}{} \\
\hline \multicolumn{2}{|c|}{ Approx. Chi-square } \\
\hline Df & 1158.74 \\
\hline Sig & 0.00 \\
\hline
\end{tabular}

For factor validity, an exploratory factor analysis should be performed on the data to determine the desired explanatory concepts. According to Petty (1995), factor analysis is a technique to achieve parsimony through the identification of the smallest number of descriptive terms to explore the maximum amount of common variance in a component matrix. A principal component analysis was the chosen extraction method. Varimax was applied prior to factor rotation, thus keeping factors with an eigenvalue of one or greater. This 
procedure was chosen to eliminate error variance.

Exploratory factor analysis is used to summarize data by grouping together variables that are intercorrelated. The scree plot (Figure 4) provides a graphic representation of the relative values of eingenvalues.

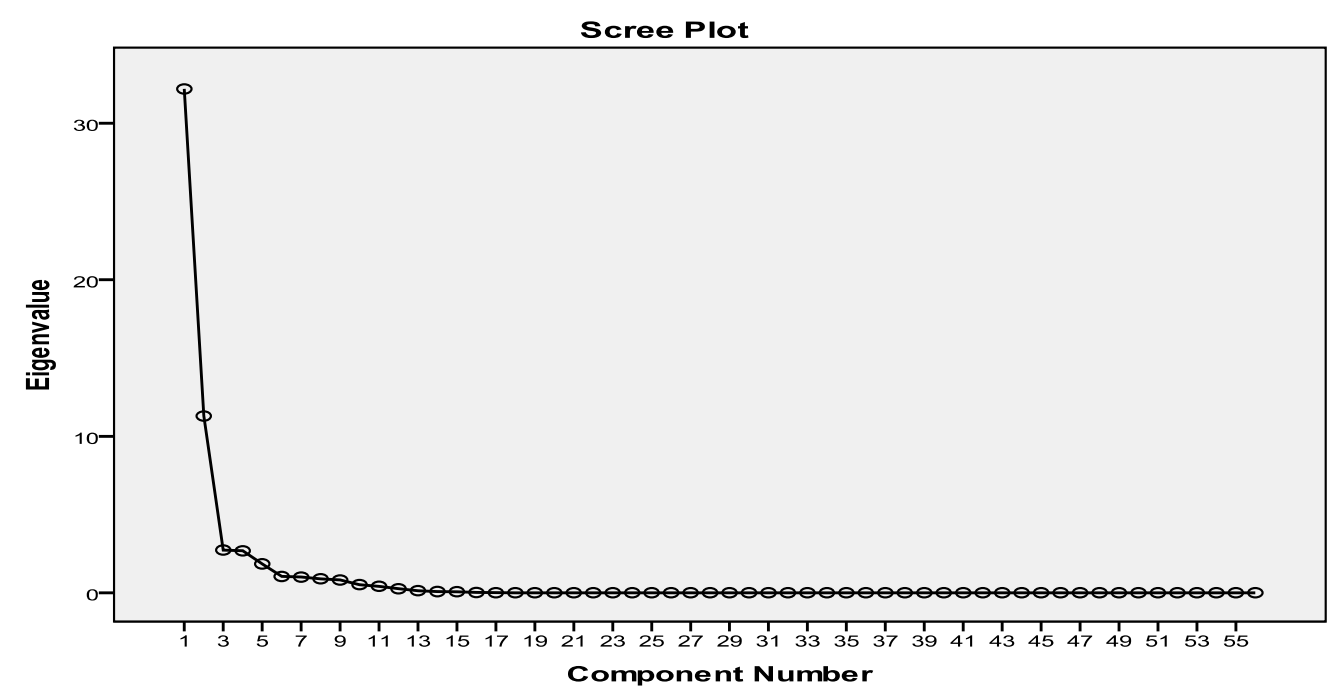

Figure 1.The Scree Plot

Table 4. Principal component analysis, $(n=425)$

\begin{tabular}{|c|c|c|c|c|c|c|c|}
\hline No & I & II & III & IV & V & VI & VII \\
\hline 1 & .49 & & & & & & \\
\hline 12 & .81 & & & & & & \\
\hline 21 & .57 & & & & & & \\
\hline 27 & .62 & & & & & & \\
\hline 29 & .54 & & & & & & \\
\hline 2 & & .41 & & & & & \\
\hline 3 & & .52 & & & & & \\
\hline 4 & & .65 & & & & & \\
\hline 14 & & .61 & & & & & \\
\hline 22 & & .42 & & & & & \\
\hline 25 & & .48 & & & & & \\
\hline 26 & & .54 & & & & & \\
\hline 28 & & .62 & & & & & \\
\hline 30 & & .74 & & & & & \\
\hline 31 & & .62 & & & & & \\
\hline 37 & & .43 & & & & & \\
\hline 38 & & .58 & & & & & \\
\hline 6 & & & .39 & & & & \\
\hline 7 & & & .43 & & & & \\
\hline 16 & & & .53 & & & & \\
\hline
\end{tabular}




\begin{tabular}{|c|c|c|c|c|c|}
\hline 19 & .74 & & & & \\
\hline 23 & .54 & & & & \\
\hline 34 & .38 & & & & \\
\hline 35 & .44 & .46 & & & \\
\hline 10 & & .54 & & & \\
\hline 11 & & .75 & & & \\
\hline 24 & & .51 & & & \\
\hline 36 & & & .39 & & \\
\hline 5 & & & .33 & & \\
\hline 15 & & & .43 & & \\
\hline 32 & & & .56 & & \\
\hline 33 & & & .55 & & \\
\hline 35 & & & & .63 & \\
\hline 36 & & & & .76 & \\
\hline 37 & & & & .39 & \\
\hline 38 & & & & .56 & \\
\hline 39 & & & & .41 & \\
\hline 40 & & & & .37 & \\
\hline 41 & & & & .52 & \\
\hline 42 & & & & .46 & \\
\hline 43 & & & & .34 & \\
\hline 44 & & & & .51 & \\
\hline 45 & & & & & .32 \\
\hline 46 & & & & & .48 \\
\hline 47 & & & & & .45 \\
\hline 48 & & & & & .57 \\
\hline 49 & & & & & .35 \\
\hline 50 & & & & & .63 \\
\hline 51 & & & & & .41 \\
\hline 52 & & & & & .64 \\
\hline 53 & & & & & .36 \\
\hline 54 & & & & & .31 \\
\hline 55 & & & & & .64 \\
\hline 56 & & & & & .73 \\
\hline 57 & & & & & .49 \\
\hline 58 & & & & & .53 \\
\hline
\end{tabular}

Note. I=Intrinsic, II=Extrinsic, III=Cultural, IV=Instrumental, V=integrative, VI=Test anxiety, $\mathrm{VII}=$ English Classroom Anxiety

Data questions are loaded into seven factors (Table 4). Five items loaded on factor1 (Intrinsic). These items were related to intrinsic motivation in learning English. There were 
Fourteen items loading on factor2 (Extrinsic). This factor reflected a positive disposition toward a community of L2 in learning English language. Thus, it was named "Extrinsic motivation". Seven items loaded on factor 3 (Cultural). This factor indicated students' focus on context is often described "Cultural motivation". Also, four items loaded on factor4 (Instrumental) that presents students' desire to learn the L2 primarily for potential concrete gains associated with L2 proficiency, so called "instrumental motivation". Four items loaded on factor 5 (Integrative) these items were related to Intention of learners to learn the language in order to better understand and knowing the people who speak that language, they called integrative motivation. In addition nine items were loaded in factor six (Test anxiety). This factor reflects students' extreme stress and anxiety during or before taking a test. Finally, fifteen items loaded on Factor seven (Classroom anxiety) that reflect learners' feeling toward the situations as threatening, there can be an adverse affect on learning therefore, this factor was named "classroom anxiety". Items that are, either factor loadings lower than .30 or crossloaded on other factors were removed from the structure.

\subsubsection{Confirmatory Factor Analyses}

There are different criteria to determine the overall fit of the models. For this study, to verify the overall structure of research model, the fitness of the model was analyzed through several indices, namely Chi-Square statistics, the Goodness of Fit Index (GFI), the Adjusted Goodness of Fit Index (AGFI), and Root Mean Square Error of Approximation (RMSEA).

Table 5. Goodness of fit indices for model

\begin{tabular}{|c|c|c|c|c|c|}
\hline & $\chi^{2}$ & GFI & AGFI & CFI & RMSEA \\
\hline $\begin{array}{c}\text { Psychological } \\
\text { Construct }\end{array}$ & 11.52 & .87 & .82 & .91 & .11 \\
\hline
\end{tabular}

Table 5 shows that all of the examined parameter estimates in the complete CFA were significant. The goodness of fit index (GFI) should be greater than .90 and the adjusted goodness of fit index (AGFI) preferably greater than .80. In this case GFI is .87 and AGFI .82 which means both values are greater than cut-off point. The reliable indicator comparative fit index (CFI) which should preferably be greater than .90, In this case CFI are .91, which more than acceptable level. The RMSEA value is .063 which indicates a good fit.

In order to understand the directional relationships between affective factors and test performance a structural model was tested using SEM after the CFA model was built. Wang (2012) pointed out that SEM provides a flexible and powerful means of simultaneously assessing the quality of measurement and examining casual relationship. He continued that construct such as ability, self-esteem, motivation, success, are essentially hypothetical construct. The SEM family is a flexible set of technique, applicable to both experimental and 
non-experimental data. According to Hoyle (2012) the specification of structural model in SEM relies heavily on the researcher's good judgment to (1) describe and measure variables of interest, while avoiding the omission of cause correlated with those represented in the model. (2) Correctly partition the variables into the mutually exclusive subsets of exogeneouse variables and endogenouse variables (3) accurately lay out patterns of presumed direct and indirect effects. (4) Properly specify the error covariance structure. In addition, SEM has been employed as a sophisticated statistical research method in studies that simultaneously examine variables in relation to academic achievement. It was also expected that FL motivation and anxiety were closely related to FL achievement (Noels et. al, 2000).

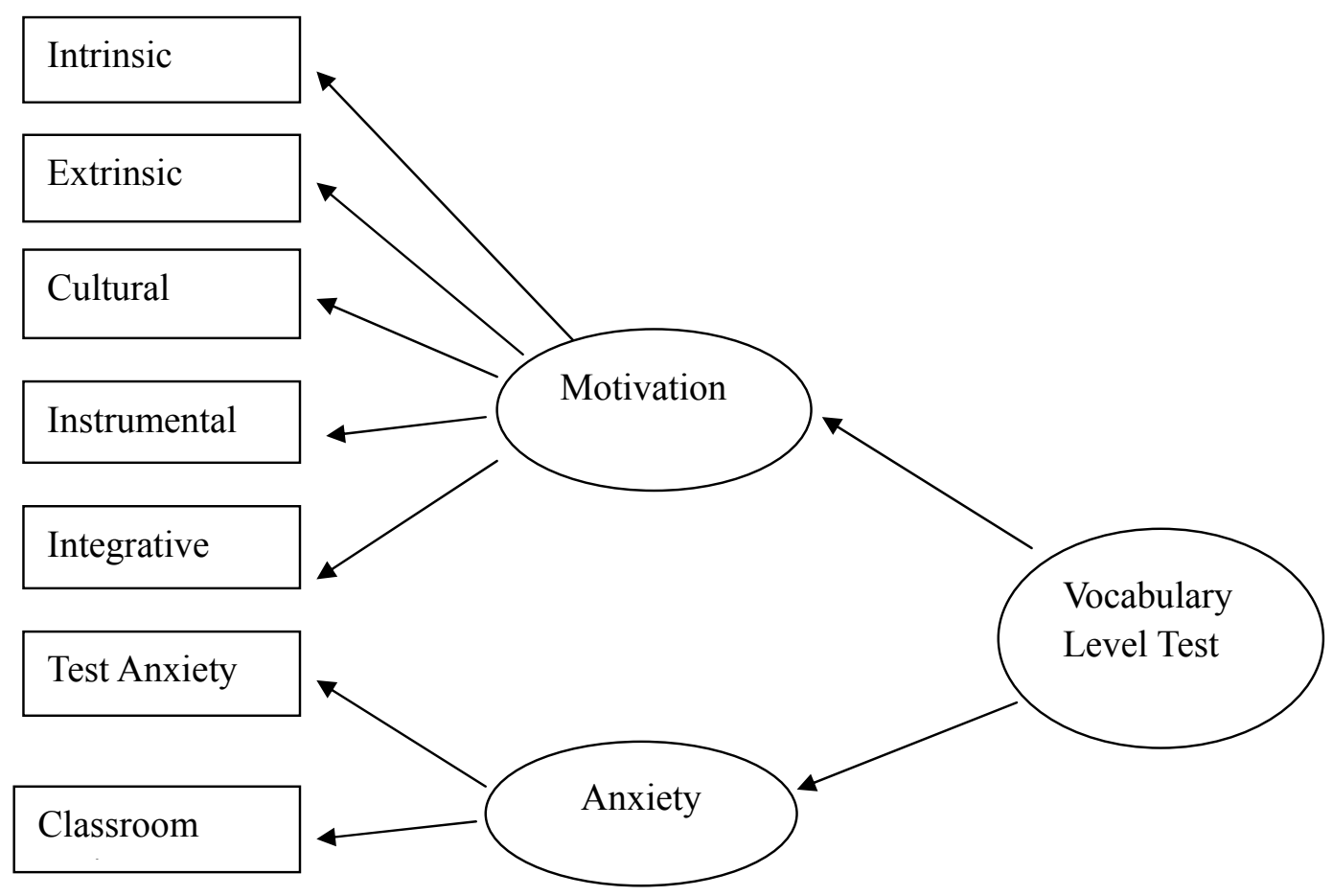

Figure 2. Hypothesized Base Model of VLT Achievement

\subsubsection{Reliability}

This general rule is to check whether the Cronbach's alpha or the reliability coefficient is smaller or larger than 0.7 .

Table 6. Reliability coefficient for all constructs.

\begin{tabular}{|c|c|}
\hline Construct & Cronbach's Alpha \\
\hline Intrinsic & .92 \\
\hline Extrinsic & .87 \\
\hline Cultural & .88 \\
\hline
\end{tabular}




\begin{tabular}{|c|c|}
\hline Instrumental & .79 \\
\hline Integrative & .95 \\
\hline Test Anxiety & .80 \\
\hline Classroom Anxiety & .93 \\
\hline
\end{tabular}

All the constructs have reliability coefficients of more than 0.7 , thus it implies that all the items from the constructs are statistically reliable and should not be dropped for further analysis, namely the descriptive and inferential analysis.

\subsubsection{Main Study}

\subsubsection{Data Collection Procedures}

The main study was conducted in June, 2014. Data collection was conducted by a researcher and university staffs. Prior to distributing the questionnaire, the students were informed of the objectives and significance of the research. The researcher asked the participants to fill out both sections of the questionnaires, one part to gain demographic information another related to the strategies that the participant may have recently used. Students received oral instruction in Farsi on how to complete the questionnaire. They were told to write the same name on both instruments and were encouraged to ask on any question on any items they did not understand. There was no time restriction in both of the questionnaires. After they had all finished filling the questionnaires, they were rewarded with a pen for their cooperation in this study.

In the second step, 97 participants answered the 2000 VLT (Vocabulary Level Test) in 40 minutes in regular class time in the next day. The researcher met with the participants three weeks following the first visit to complete the VLT. The researcher announced the participants two to three days prior to meeting as a reminder of the test time by their teacher.

\subsubsection{Data Analysis Procedures}

The data analysis procedure in the present study was consisting of two sections. In the first one data screening processes were followed to enhance the analyses conducted in this study prior to the main data analysis. Various SPSS procedures for missing data, outliers among cases, and normality were examined. In the latter, Data were subjected to a structural equation modeling with Lisrel 8.8 In order to derive a directional relationships between affective factors and test performance .

\subsection{Examination of Data Entry and Missing Data}

First, students' test scores were verified case by case to the returned questionnaire $(n=465)$. Then the pattern of missing data was examined carefully to determine whether the missing values were random. In examining the completeness of returned questionnaire, it was found that 40 questionnaires contained missing data for some of the construct measurement sections. Among those case, 28 questionnaires had at least $30 \%$ or more of the overall questionnaire unanswered. It was found that in 12 cases, retuned questionnaires consist of 
incomplete identification information like gender. This biased toward females few missing response in different scale were found randomly. These procedures collectively led to a sample size of 425 .

\subsection{Assessment of Normality and Outliers}

Data distribution with either a highly skewed nature or with high Kurtosis is indicative of non-normality which has random effects on specification or estimation (Hall and Wang, 2005). An outlier is a case with an extreme value on one variable (univariate outlier) or a strange combination of values on two or more variables (multivariate outlier) that distorts statistics (Tabachnick \& Fidell, 2007).

The two statistics that score distribution are the indices of skewness and kurtosis. As a rule of thumb, values for skewness and kurtosis of between -2 and +2 indicate a reasonably normal distribution. Most of the items were normally distributed with skewness and kurtosis values close to zero. No extreme nonnormal distribution was found (Ruppert, 2004).

Table 7. Descriptive statistics

\begin{tabular}{|c|c|c|c|c|}
\hline Variable & Mean & SD & Skewness & Kurtosis \\
\hline Intrinsic & 4.65 & .66 & .74 & 1.17 \\
\hline Extrinsic & 3.90 & .93 & -1.44 & .27 \\
\hline Cultural & 2.35 & 1.44 & 1.87 & 1.14 \\
\hline Instrumental & 4.65 & 1.05 & .87 & 1.35 \\
\hline Integrative & 2.25 & 1.76 & 1.35 & -.31 \\
\hline T Anxiety & 2.86 & 1.39 & 1.70 & 1.72 \\
\hline C Anxiety & 3.27 & 1.65 & -1.25 & -.39 \\
\hline
\end{tabular}

\section{Results}

In this study the data were processed by multivariate analysis, namely structural equcational modeling. Structural Educational Modeling (SEM) is designed to evaluate how well a proposed conceptual model that contains observed indicators and hypothetical constructs explains or fit the collected data. If the T-value are between .1 .96 and 1.96(-1.96< T-value $<$ 1.96) then declared indication of no significant effect between the latent variable (Mueller, 1996).

\subsection{Female Students vs. Male Students}




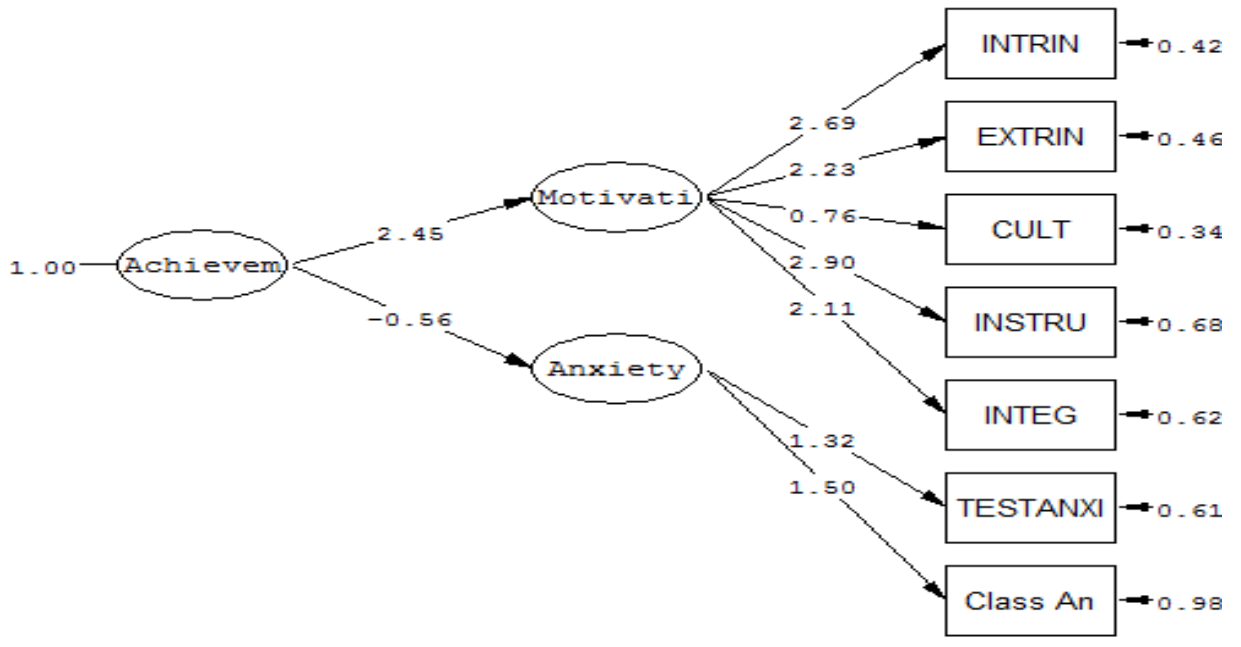

Figure 3. The Path Diagram of Vocabulary Achievement Motivation and Anxiety in the Male Group

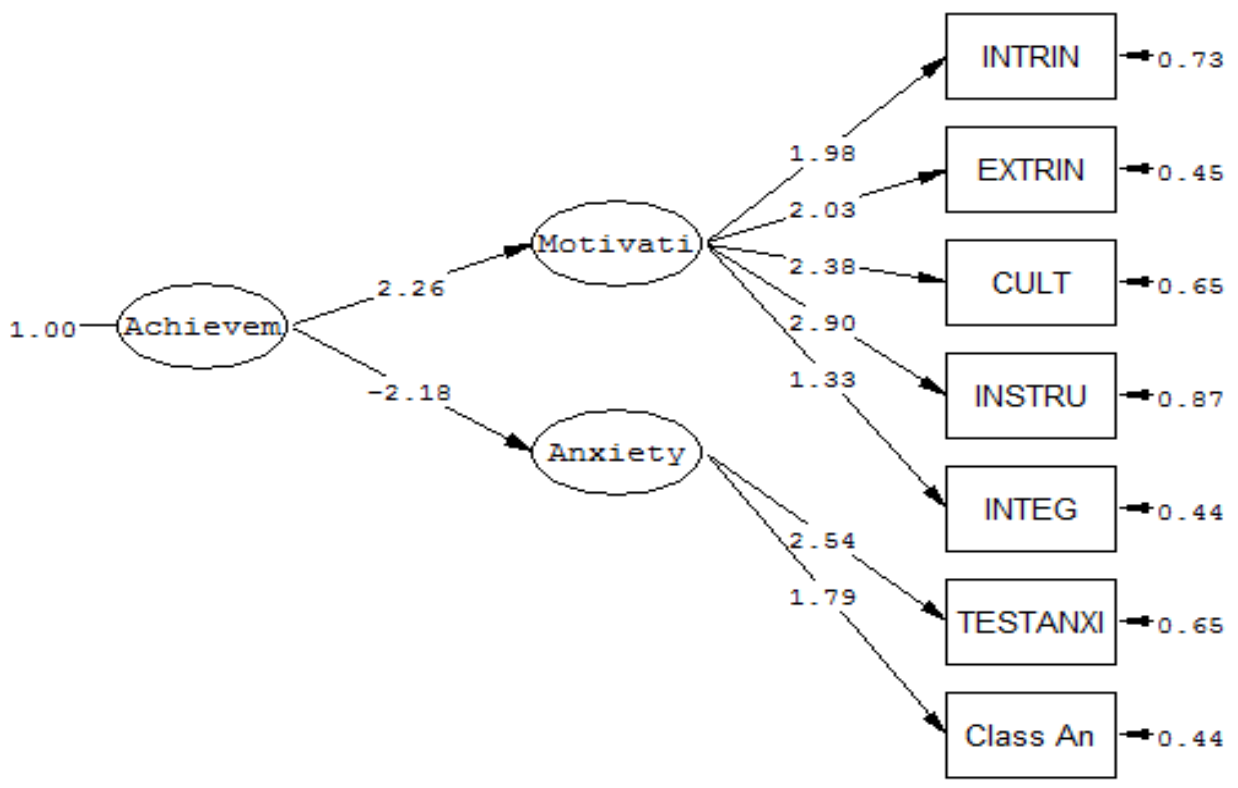

Figure 4. The Path Diagram of Vocabulary Learning Motivation and Anxiety in the Female Group

In the male model, the goodness-of-fit indexes showed that the model fit the data (GFI $=.94$, AGFI=.91 RMSEA=.07), and there was a moderately path coefficients $(r=2.45)$ between the factors of motivation and Vocabulary learning. Meanwhile, anxiety had a negative relation on English vocabulary learning. To be specific, instrumental motivation (Path coefficients $=2.90$ ), had a strong path estimate on vocabulary learning, and cultural motivation (Path coefficients $=.76$ ) had a weaker effect on learning vocabulary. On the other hand, the 
relationship between vocabulary use and test anxiety (Path coefficients $=.58$ ) was at a lower level than the English language class anxiety (Path coefficients $=.50)$ (See Figure 3).

Figure 4 graphically demonstrates the standardized coefficients of the examined variables in Female group. With the standardized coefficients ranging from -2.18 to 2.90 , four out of five manifest variables coefficients were significant, demonstrating that the factors were well represented by their respective manifest variables. To be specific, instrinsic motivation (Path coefficients $=1.98$ ), Extrinsic motivation (Path coefficients $=2.03$ ), cultural motivation (Path coefficients $=2.38$ ), instrumental (Path coefficients $=2.90$ ) and integrative motivation (Path coefficients $=1.33$ ) had a path estimate to vocabulary learning. Meanwhile, Anxiety with two variables (Test Anxiety and Classroom Anxiety) had negative coefficients of 2.54 and 1.79 respectively. In other words, anxiety had a negative relation on learning motivation in the male group (See Figure 4).

\subsection{Proficiency Level}

The second research question investigated the comparison between upper-intermediate and lower-intermediate level test.

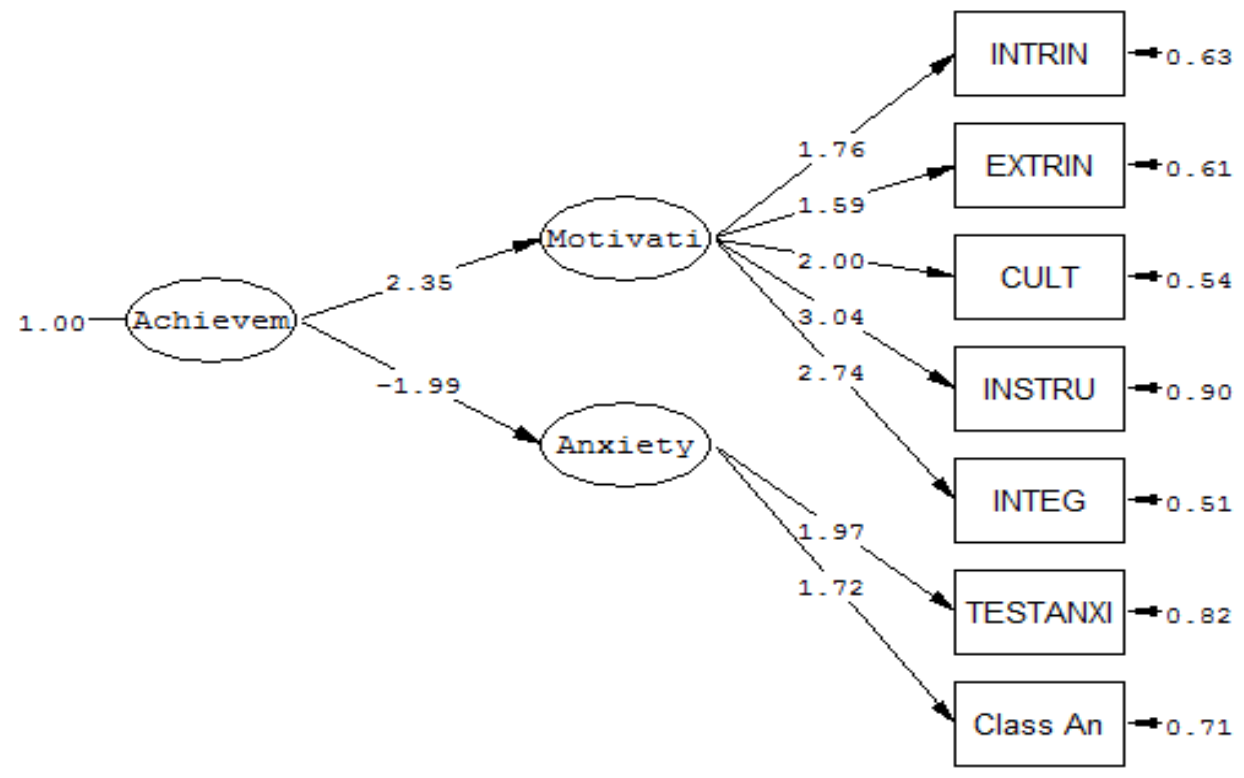

Figure 5. The Path Diagram of Vocabulary Learning Motivation and Anxiety in the Upper-intermediate Group 


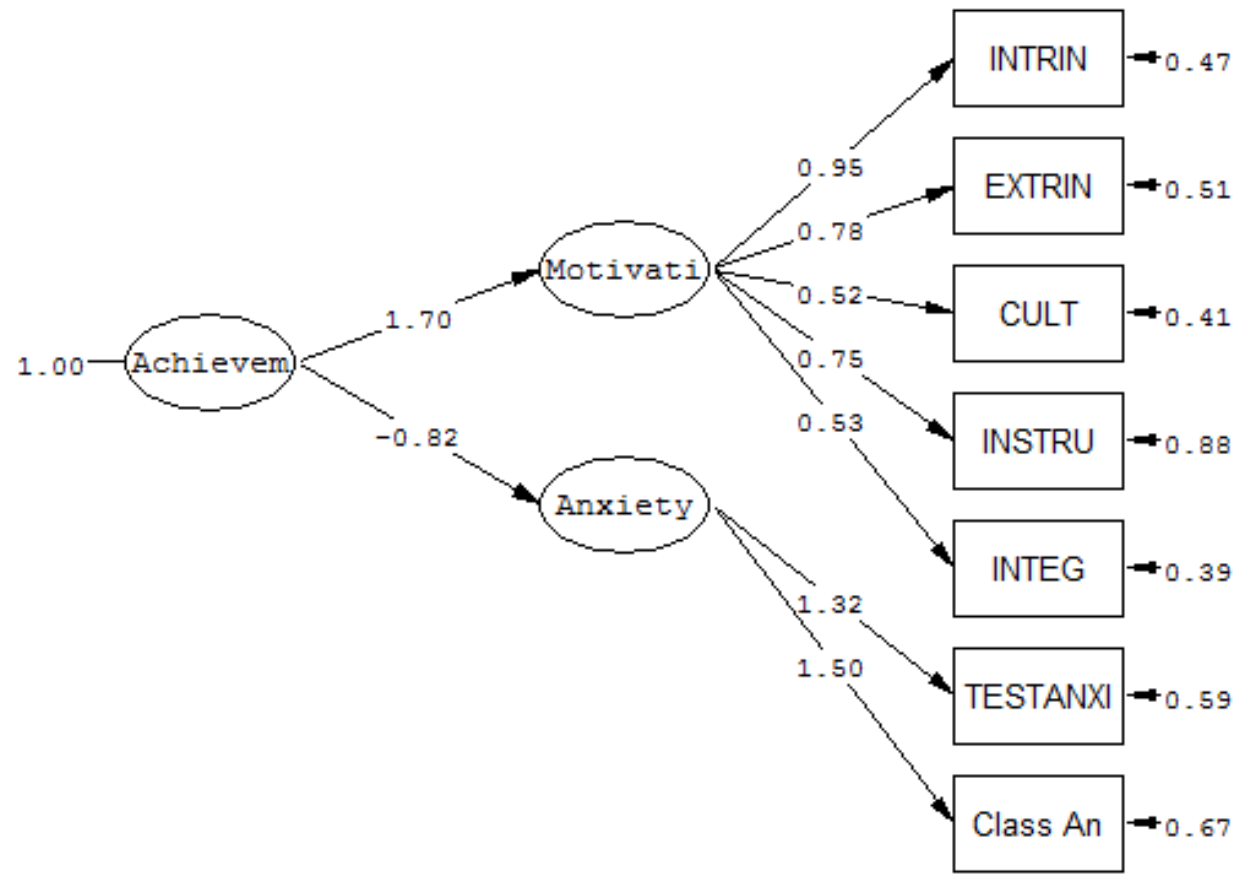

Figure 6. The Model of English Learning Motivation and Anxiety in Lower intermediate

By comparing goodness-of-fit indexes between groups it confirmed that upper-intermediate level of vocabulary achievement resulted (GFI=.92, AGFI=.94, CFI=.87, RMSEA=.09), good index than lower-intermediate group. Also it resulted a weakly path of coefficients $(r=-1.99)$ between the factors of anxiety and vocabulary test achievement. At whole, it appeared that anxiety had a negative relation on learning motivation in both groups. In particular, instrumental motivation (Path coefficients $=.75$ ), had a weak path estimate to learning motivation, and integrative motivation (Path coefficients $=.53$ ) had a very weak relationship with vocabulary achievement. By contradistinction, English language class anxiety (Path coefficients $=.1 .50$ ) was at a higher level than English use and test anxiety (Path coefficients $=1.32$ ) (Figure 6).

\section{Conclusions}

This research study aimed at examining students' motivations and anxiety levels towards English language learning in Iranian university context. Using the survey method, in this study the measures for the intrinsic and extrinsic motivation were tailored from Schmidt, Boraie and Kassabgy (1996). The measures for instrumental, integrative and cultural interests were tailored from Dörnyei (1990) and were piloted to examine its validity and reliability. The results of this study have confirmed a number of assumptions and theories about L2 motivation. With respect to the students' motivation, in both the male and female groups the results showed that instrumental motivation was the crucial source of the students' motivation 
toward learning the English vocabulary learning and also it was found to have statistically significant relationship with such proficiency.

The results of this study are in line with Swanes's study (1987) that compared learners between Westerns and Asians learners and concluded that westerners have "luxury motives for coming to Norway to study", whereas for students from Asian, their motivation is "to get an education". In terms of their learning anxieties, male and female groups are varied to some extent. In the male group, English class anxieties are at a higher level than English use and test anxiety. On the contrary, English use and test anxiety of the female group are at a higher level than their English class anxieties. In other words results indicate that male learners worry about making mistake, embarrassing to volunteer answer in English language class , afraiding English language teacher to correct mistake. While female learners are not ease during test, worry about the consequence of failing in English.

With respect to varied English language proficiency groups, anxiety only had a slight effect on English learning motivation of the Upper-intermediate group. The level of test anxiety decreases at higher grades and the students who have higher scores are less anxious than the ones who have lower marks. Second, test anxiety producing factors are low level proficiency of the learners, negative attitudes of teachers towards test applications, students' attitudes towards language learning, test invalidity, fear of negative evaluation, bad experiences on tests, time limitation and pressure, the difficulty of course contents and parental expectations. Anxious students often know more than they can demonstrate on a test or other high-staking setting. They may lack useful testing-taking skills, or they may have learned the materials but "freeze and forget". Thus anxiety can interfere at one or all three points: attention, learning, and testing (Benjamin \& Lin, 1987).

According to Horwitz et al. (1986), educators have two options when dealing with anxious students: (1) they can help them learn to cope with the existing anxiety provoking situation; or (2) they can make the learning context less stressful. When students face stressful situations in schools, they can use three kinds of coping strategies: problem solving, emotional management, and avoidance. Problem-focused strategies might include planning a study schedule, borrowing good notes, or finding a protected place to study. Emotion-focused strategies are attempt to reduce anxious feeling for instance by using relaxation.

\section{References}

Alexander, P. A., \& Murphy, P. K. (1998a). A test of cognitive and motivational dimensions of domain learning. Journal of Educational Psychology, 90, 435-447. http://www. anitacrawley. net/ Articles/Murphy.pdf

Bachman, L. (1990). Fundamental considerations in language testing. Oxford: Oxford University Press.

Baker, L., \& Wigfield, A. (1999). Dimensions of children's motivation for reading and their relations to reading activity and reading achievement. Reading Research Quarterly, 34, 152177. https://www.msu.edu/ dwong/CEP991/CEP991Resources/Baker\%26WigfieldMotivR dng.pdf 
Cassady, J. C. (2004a). Adapting the cognitive test anxiety scale for use with Argentinean University Students. International Journal of Testing, 9, 3-19, 2009. www.researchgate.net/...Cognitive_Test.../e0b49526666a340285.pdf

Chambers, G. N. (1999). Motivating language learners. Clevedon, England: Multilingual Matters.

Clement, R. (1986). Second language proficiency and acculturation: An investigation of the effects of language status and individual characteristics. Journal of Language \& Social Psychology, 5, 271-290. http://jls.sagepub.com/content/5/4/271. pdf.

Gardner, R. C. (1983). Learning another language: A true social psychological experiment. Journal of Language \& Social Psychology, 2, 219-239.jls.sagepub.com/content/2/2-3-4/pdf

Dörnyei, Z. (1994). Motivation and motivating in the foreign language classroom. Modern Language Journal, 78, 273 - 284. http:// seas3 .elte. hu / coursematerial / RyanChristopher /Dornyei(1994)_Foreign_Language_Classroom.pdf

Dörnyei, Z. (1997). Psychological processes in cooperative language learning: Group dynamics and motivation. Modern Language Journal, 81, 482-493. www. Finchpark.com/courses/.../group-dynamics-motivation.pdf.

Ellis, R. (1997). Second language acquisition. Oxford Introduction to Language Study. Oxford University Press. (Ninth edition, 2003)

Horwitz, E. K. (1988) "The Beliefs about Language Learning of Beginning University Foreign Language Students". The Modern language Journal, 72, 283-294. onlinelibrary.wiley.com/doi/10.1111/j.1540-4781.1988...x/pdf

Keller, J. M. (2008). An integrative theory of motivation, volition, and performance. Technology, Instruction, Cognition, and Learning, 6(2). Insysprelimexamprep. wikispaces. com / .../Keller_2008_Integrative_Theory. pdf

Matsuda, A. (2002). Representation of users and uses of English in beginning Japanese EFL textbooks. JALT Journal, 24(2), 80-98. jalt-publications.org/files/pdf-article/jj-24.2-art5.pdf

Maslow, A. H. Conflict, frustration, and the theory of threat. J. abnorm. (soc.) Psychol., 1943, 38, 81-86. http://www.amazon.com/Conflict-Frustration-And-Theory-Threat-ebook/dp/pdf.

MacIntyre, P. D., \& R. C. Gardner (1991) "Investigating Language Class Anxiety Using the Focused Essay Technique". The Modern Language Journal, 75, 296-313. http://faculty.capebretonu.ca/pmacintyre/research_pages/journals/focused_essay1991.pdf

McDonough, J., \& Shaw, C. (1993). Materials and Methods in ELT. Blackwell. McKay, S. L. (2002). Teaching English as an international language: rethinking goals and approaches. Oxford University Press.

Najafi, F., \& Behjat, F (2013). The rise and fall of Iranian female students' motivation at different levels of language proficiency from high school. Scientific Publishing group, 2013; 1(4), 166-177.article.sciencepublishinggroup.com/pdf/10.11648.j.ij11.20130104.21.pdf 
Nation, I. S. P. (1990). Teaching and Learning Vocabulary. Heinle and Heinle, New York. Nichols, J. G., \& Miller, R. B. (1994). Cooperative learning and student motivation. Contemporary Educational Psychology, 19, 167-178. http://files.eric.ed.gov/fulltext /ED387341.pdf

Pintrich, P. R., Marx, R. W., \& Boyle R. A. (1993). Beyond cold conceptual change: The role of motivational beliefs and classroom contextualfactors in the process of conceptual change. Review of Educational Research, 63, 167-199. http: // rer.sagepub.com/ content/63/2/167. pdf

Reeve, J. (2006). Teachers as facilitators: What autonomy-supportive teachers do and why their students benefit. Elementary School Journal, 106, 225-236. http://johnmarshallreeve.org/yahoo_site_admin1/assets/docs/Reeve2006.4731443.pdf

Robinson, K. (ed.) (1990). The Arts 5-16: A Curriculum Framework. Essex: Oliver \& Boyd.

Schunk, D. H., \& Rice, J. M. (1985). Verbaliza-tion of comprehension strategies: Effects on children's achievement outcomes. Human Learning, 4, 1-10. http://libres.Uncgedu/ir/ uncg/f/D_Schunk_Verbalization_1986.pdf

Tabachnick B.G., \& Fidell, L.S. Using Multivariate Statistics. Boston: Pearson; 2007.

Tseng, W. T., Schmitt, N. Toward a model of motivated vocabulary learning: A structural equation. Language Learnin, 357-400. www.norbertschmitt.co.uk/.../tseng-w-t-and-schmittn-(2008)-towards-a-self-Modeling Approach.

Urdan, T., \& Maehr, M. L. (1995). Beyond a two-goal theory of motivation and achievement: A case for social goals. Review of Educational Research, 65(3), 213- 243. rer.sagepub.com/content/65/3/213.pdf.

Oxford, R., \& Shearin, J. (1994). Language learning motivation: Expanding the theoretical framework. Modern Language Journal, 78, 12-28. onlinelibrary. wiley.com /doi/ 10.1111 /j. 1540-4781. 1994...x/pdf

\section{Copyright Disclaimer}

Copyright for this article is retained by the author(s), with first publication rights granted to the journal.

This is an open-access article distributed under the terms and conditions of the Creative Commons Attribution license (http://creativecommons.org/licenses/by/3.0/). 